\title{
La traducción de la subtitulación y los realia en la combinación lingüística árabe/español. Estudio y análisis
}

Moulay-Lahssan Baya Essayahi. Universidad de Granada

Chadia El Mokhlik. Universidad de Granada

Recepción: 22.07.2018 | Aceptado: 2.010.2018

Correspondencia a través de ORCID: Moulay-Lahssan Baya

iD $0000-0002-3066-8082$

Citar: Baya Essayahi, ML. y El Mokhlik, Ch. (2018). La traducción de la subtitulación y los realia en la combinación lingüística árabe/español. Estudio y análisis. ReiDoCrea, 7, 298-317.

\begin{abstract}
Resumen: La traducción es un cambo sobre el que han investigado diversas escuelas; una actividad que ha desembocado en varias modalidades; y una práctica con ingeniosas técnicas y estrategias para su realización. El principal reto al que se enfrenta todo traductor es la traducción de los referentes culturales, denominados en este artículo realia, un reto que se hace mayor cuando se trata de traducir textos orales en subtítulos; se trata de una de las modalidades de la traducción audiovisual más solicitadas actualmente debido al mundo digital en el que vivimos, ya que esta permite la accesibilidad a personas con diversidades funcionales. Objetivo: Por ello, el presente artículo se centra en la subtitulación como modalidad de la traducción audiovisual, de la combinación lingüística árabe/español, con una parte teórica aplicable a un marco práctico en el que se lleva a cabo una subtitulación real, con retos reales, y las técnicas que se han aplicado para la traducción de los referentes culturales. Conclusiones: Tras el estudio, clasificación y análisis de los referentes culturales, observamos que la mayoría de los realia se encuadran en más de una categoría, y por lo tanto pueden tener más de una connotación que se debe tener muy en cuenta a la hora de traducir.
\end{abstract}

Palabras clave: Traducción Subtitulación | Referencias Culturales

The translation of subtitling and the realia in the Arabic/Spanish language combination. Study and analysis

Abstract: Translation is a field of study that several schools have investigated about. It is an activity that has led to several modalities and a practice that use ingenious techniques and strategies for its realization. The main challenge that every translator faces is the translation of cultural references, called realia along this article, and which becomes a bigger challenge when translating oral texts into subtitles. Nowadays, it is one of the most requested forms of audiovisual translation due to the digital world we live in, and because it allows people with functional diversity access to it. Objective: For this reason, this article focuses on subtitling as a modality in audiovisual translation, from Arabic to Spanish, with a theoretical part applicable to a practical framework in which a real subtitling is carried out, with real challenges, and the techniques that have been applied for the translation of cultural references. Conclusions: After the study, classification and analysis of cultural referents, we observed that most of the realia fall into more than one category, and therefore may have more than one connotation that must be taken into account when translating.

Keywords: Translation Subtitling | Cultural References

\section{Introducción}

Este va dirigido a todo tipo de lectores, desde estudiantes hasta profesionales en el ámbito de la traducción, e incluso a aquellos interesados en el tema. Eso sí, se espera que este trabajo pueda ser de utilidad, desde el punto de vista teórico y práctico, para traductores, precisamente, de la combinación lingüística español-árabe, y que sea la base para una investigación mucho más amplia sobre las técnicas de traducción de los referentes culturales, denominados en este estudio realia, en la subtitulación de o hacia la lengua árabe.

La carrera de Traducción e Interpretación consiste, además de otras cosas, en la formación de futuros traductores, ya sea en textos especializados o de carácter 
general. Se trata de una trayectoria en la que estos traductores han de enfrentarse a posibles retos de traducción y han de ser capaces de resolverlos para realizar una traducción de calidad, transmitiendo así el mensaje correctamente. En este trabajo, se hace hincapié en la traducción de los referentes culturales como uno de los principales retos de la traducción, precisamente del árabe al español, dos lenguas con una enorme carga cultural. Asimismo, en esta carrera de la Universidad de Granada, los alumnos de Traducción e Interpretación cursan en su último año de carrea la asignatura de Traducción Multimedia, una disciplina que "abarca las modalidades de traducción en cuyos textos originales interfieren como mínimo dos códigos; incluye la traducción audiovisual, la traducción de programas informáticos y la de productos informáticos multimedia" (Hurtado, 2001: 72). Se trata de una asignatura en la que los futuros traductores adquieren nuevas habilidades de traducción audiovisual, precisamente de la subtitulación, una de sus modalidades. La subtitulación, dentro de lo que cabe, es una modalidad nueva, de la cual queda mucho por descubrir, y no pocas cuestiones que tratar, sobre todo, en la vertiente español-árabe, siendo esta última una lengua compleja, con sus particularidades y con una gran carga cultural religiosa. De ahí surgió la idea de basar este trabajo en la traducción de los referentes culturales en la subtitulación.

El producto audiovisual seleccionado para la elaboración de este estudio es un vídeo que constituye una crítica fundamentada sobre el concepto de la inimitabilidad científica en el Corán; un corpus de estudio con la suficiente carga de referentes culturales relacionados con la lengua árabe y con la religión islámica para observar las dificultades que surgen en su subtitulación.

\section{Objetivos y metodología}

El presente trabajo parte de los siguientes objetivos generales:

1. Exponer la complejidad de definir la traducción aportando diferentes definiciones según varios autores.

2. Describir la subtitulación como modalidad de la traducción audiovisual.

3. Exponer la complejidad de la subtitulación en el contexto de la lengua árabe, por las variedades dialectales que componen esta lengua.

4. Difundir el contenido del producto audiovisual seleccionado mediante una subtitulación, traduciendo su contenido del árabe al español, para que llegue al público hispanohablante, en general.

En cuanto a los objetivos específicos, destacamos los siguientes:

1. Describir el proceso traductológico que se sigue en la subtitulación del árabe al español, aplicada al vídeo extraído del canal de YouTube "TVIslamScience".

2. Señalar las dificultades que surgen en el proceso, tanto de traducción como de subtitulación.

3. Exponer las estrategias traductoras que se han aplicado para solucionar retos de traducción.

4. Resaltar la importancia de la clasificación y el análisis de los referentes culturales previamente a su traducción para poder reflejarlos de la forma más óptima en la lengua meta.

5. Aplicar las técnicas de traducción adecuadas para la traducción de los realia.

6. Descubrir las técnicas de traducción que más se han utilizado para la traducción de los referentes culturales del árabe al español.

7. Observar las categorizaciones temáticas que prevalecen en la clasificación de los realia extraídos del corpus objeto de estudio.

\section{Metodología}


Para Para llevar a cabo el presente trabajo ${ }^{1}$ se han seguido determinados pasos que han sido claves. Una vez acordado y decidido el tema objeto de estudio, fue necesaria la elección de un producto audiovisual sobre el que basar nuestra investigación; un producto audiovisual con la carga necesaria de referentes culturales suficientes para su análisis. Finalmente, se ha elegido el vídeo del canal de YouTube TVIslamScience titulado ما صحّة نظرية الإعجاز العلمي في القرآن الكريج, título que hemos traducido así: ¿Es cierta la inimitabilidad científica en el Corán? A continuación, se ha llevado a cabo la transcripción de dicho archivo, es decir, se ha reflejado por escrito el texto oral. La transcripción íntegra del vídeo se recoge en el anexo 1 de este estudio, ya que así es más práctico y útil para el lector interesado en su cotejo con la traducción.

Tras finalizar la transcripción del contenido del archivo audiovisual, el siguiente paso fue su traducción, donde en el caso de las aleyas fue indispensable, después de consultar varias fuentes, acudir a la traducción del Corán (Sheikh Isa García, 2013), disponible en internet. Una vez finalizada la traducción, se reflejó en subtítulos, a través de la descarga del vídeo de YouTube en el formato y extensión adecuada para que el programa informático utilizado, Subtitle Workshop, de descarga gratuita y con diversas versiones, pudiera reconocerlo y reproducirlo.

La subtitulación, como se explica a continuación, supone restricciones que afectan a la traducción, por lo que se ha decidido prescindir de ciertas expresiones por falta de espacio. Una vez introducidos los subtítulos de forma que cumpliesen con las normas del número de caracteres, el siguiente paso fue la sincronización de los subtítulos, una tarea laboriosa ya que requiere mucha concentración porque un incorrecto ajuste de los tiempos supone la superposición de los subtítulos, e incluso su desaparición. Este proceso se explica más detalladamente en uno de los apartados.

El producto audiovisual, traducido y subtitulado, servirá para realizar un marco práctico que consta de un apartado dedicado al análisis, clasificación y técnicas aplicadas para la traducción de los realia extraídos del mencionado vídeo. Para esta sección, se analizarán siete realia, que consideramos, lo cual nos ayudará a extraer las conclusiones pertinentes, y así alcanzar los objetivos de los que parte este trabajo.

El análisis de los realia consistió, primero, en la definición de cada realia, luego su clasificación en categorías y subcategorías siguiendo la tabla de Igareda (2011: 1921), recogida y desarrollada, más adelante, en el marco teórico. Tras este análisis de los realia, identificamos las técnicas de traducción empleadas, y efectuamos un breve comentario sobre las técnicas utilizadas, también descritas en el marco teórico. $\mathrm{Y}$, finalmente, dedicamos un apartado a los resultados de las técnicas que más se han utilizado para la traducción de los referentes culturales del producto audiovisual mencionado.

\section{Fundamentos teóricos y estado de la cuestión}

\subsection{La traducción como disciplina}

Es difícil la traducción en una simple frase que abarque absolutamente todo lo que implica. Hay un gran bagaje detrás de la traducción que es necesario conocer, así como múltiples teorías, distintos tipos y modalidades de traducción y enfoques. En resumen, el concepto de la traducción es mucho más amplio de lo que parece.

\footnotetext{
${ }^{1}$ Este artículo es el resultado de un Trabajo de Fin de Grado presentado y defendido en la Universidad de Granada por la alumna Chadia El Mokhlik, bajo la dirección del profesor Moulay-lahssan Baya Essayahi durante el curso académico 2017-2018.
} 
Además de centrarnos en la definición de la traducción como tal, existen precedentes históricos de relevante importancia dentro de este contexto. Dada la temática de este trabajo, se puede considerar que es conveniente hacer un breve repaso sobre la historia de la traducción, una historia que finalmente ha dado lugar a las diversas definiciones que hoy conocemos. Además, hemos de destacar y profundizar en una de las modalidades existentes, es decir, la traducción audiovisual (TAV), ya que es el método de traducción que aplicaremos en la parte práctica de este trabajo.

Basándonos en los diferentes autores que han escrito sobre la traducción, vemos que las definiciones que han sido aportadas para la traducción son muchas. Esto se debe a los múltiples enfoques teóricos y prácticos que se han hecho de la traducción, y a la complejidad que encierra la traducción a su vez. Los principios básicos que rigen la traducción son la primacía de la comunicación y la adecuación a la lengua de llegada, el sentido, el contexto, los aspectos culturales, el destinatario de la traducción y la finalidad de la traducción. Asimismo, las definiciones de la traducción se centran en un principio u otro dependiendo del enfoque teórico de cada autor. Algunas definiciones se centran en la consideración de la traducción como una actividad entre lenguas, es decir, la traducción es "pasar de una lengua A a una lengua B para expresar la misma realidad" (Vinay y Darbeltnet, 1958). Esta definición, propia de las teorías lingüísticas, no sitúa la traducción en el plano del habla, sino que solo se centra en los elementos lingüísticos, y por lo tanto podría considerarse como incompleta. Otras definiciones inciden en el aspecto textual, reivindicando el carácter textual teniendo en cuenta la importancia del sentido. Como respuesta a la anterior definición de Vinay y Darbeltnet, Seleskovitch y Lederer (1984: 256) afirman que "traducir significa transmitir el sentido de los mensajes que contiene un texto y no convertir en otra lengua en la que este está formulado" y añaden que traducir es "un acto de comunicación y no de lingüística". Otra definición que incide en el carácter textual de la traducción es la de House (1997: 29) cuando define la traducción como "la sustitución de un texto en la lengua de partida por un texto semántica y pragmáticamente equivalente en la lengua meta".

Desde otras perspectivas, se señala la influencia del contexto haciendo hincapié en el hecho de que la traducción es un acto de comunicación. Según Hatim y Mason (1990/1995: 13), la traducción es "un proceso comunicativo que tiene lugar en un contexto social". Por otro lado, el aspecto cultural en la traducción cobra importancia en la definición de Snell Hornby (1988) cuando afirma que la traducción es "un acto transcultural", así como en la definición de la traducción como "ecuación cultural" de Hewson y Martin (1991). En cuanto al principio de la finalidad traductora mencionado previamente, Reiss y Vermeer (1984/1996: 80) plantean que "el principio dominante de toda traslación es su finalidad", premiando así dicho principio por encima de los demás.

Finalmente, cabe mencionar que el proceso traductológico para realizar una traducción es de suma importancia y, por lo tanto, es un aspecto que hay que tratar a la hora de definir la traducción. El proceso traductor conlleva una descodificación de unidades lingüísticas teniendo en cuenta los elementos extralingüísticos y la complejidad de operaciones mentales que intervienen en él (Hurtado, 2001: 39). "El proceso de traducción está más relacionado con operaciones de comprensión y reexpresión que de comparación de lenguas" (Seleskovitch y Lederer, 1984: 18).

\subsection{La Traducción Audiovisual (TAV)}


Basándonos en toda una documentación y en la información que nos proporcionan los estudios sobre la traducción, vemos que durante la época moderna surgieron nuevas modalidades de la traducción. Hasta el siglo XX, todas las reflexiones giraban en torno a la traducción escrita, pero con la aparición de modalidades como la interpretación, el doblaje, la subtitulación, etc., las investigaciones diversificaron su rumbo para centrarse también en la traducción oral y, en este caso, en la traducción audiovisual. La aparición del cine y la gran importancia que cobró en todo el mundo dio lugar, sin duda, a la traducción audiovisual, convirtiéndola así en un tipo de traducción más reconocida e indispensable.

En la traducción de textos audiovisuales, aunque lo que se traduce es el código lingüístico, también influyen otros códigos. En este caso, el medio determina la modalidad, es decir, los textos audiovisuales requieren modalidades de traducción específicas como las voces superpuestas, el doblaje, la subtitulación o la interpretación simultánea de películas, todo ello en función del texto audiovisual que se vaya a traducir.

Existen varios géneros audiovisuales, y Agost $(1996,1999)$ realiza la siguiente clasificación: dramáticos (películas, series, telenovelas, etc.), informativos (documentales, reportajes, programas divulgativos, entrevistas, debates, etc.), publicitarios (anuncios, campañas institucionales de información, publirreportaje, propaganda electoral, etc.) y de entretenimiento (crónica social, concursos, magazines, horóscopo, etc.).

La traducción audiovisual hace referencia a la traducción para cine, televisión o vídeo; son textos audiovisuales en los que interfieren como mínimo dos códigos: el lingüístico, el visual y, a veces, el musical (Hurtado, 2001: 77). Otros autores, sin embargo, desarrollan mucho más este enfoque, como Chaume (2001: 77-78), quien afirma que los textos audiovisuales transmiten información a través de canales visuales y acústicos que se codifica mediante distintos sistemas de significación: el código lingüístico, el paralingüístico, el musical y de efectos especiales, el de colocación del sonido, los iconográficos, los fotográficos, el de movilidad, el de planificación, los gráficos y los sintácticos o de montaje. De entre todos estos códigos, el lingüístico es el de mayor importancia, ya que sin él no nos sería posible hablar de traducción.

\subsubsection{La subtitulación como modalidad de la TAV}

Como hemos podido observar, existen varias modalidades de traducción audiovisual; sin embargo, nos vamos a centrar en la modalidad de la subtitulación, al ser el tema principal de nuestra investigación, que consiste en incorporar un texto escrito (subtítulos) en la lengua meta a la pantalla en donde se exhibe una versión original, de modo que estos subtítulos coincidan aproximadamente con las intervenciones de los actores de la pantalla (Chaume, 2004: 33).

Díaz Cintas y Remael (2009: 13-24) diferencian cinco tipos de subtitulado dependiendo de su función y su destinatario, y los clasifican en cinco categorías. La categoría de subtítulos según los parámetros lingüísticos engloba dos tipos de subtítulos: intralingüísticos e interlingüísticos. La diferencia entre ambos es clara: los subtítulos intralingüísticos no implican una traducción, sino una reformulación escrita de lo que se dice en el texto oral, y pueden ser subtítulos para personas con diversidad funcional auditiva, subtítulos para dialectos o acentos de la misma lengua, subtítulos con fines didácticos, etc.; mientras que los subtítulos interlingüísticos, en cambio, implican necesariamente una traducción de un idioma a otro, y son uno de los principales tipos de subtítulos (Díaz Cintas y Remael, 2009: 17). En este trabajo, 
haremos uso de este tipo de subtítulos para alcanzar la finalidad de hacer llegar el texto audiovisual en árabe a un público hispanohablante.

Por otra parte, los subtítulos pueden haber sido previamente elaborados o elaborarse a tiempo real o en directo; abiertos o cerrados, es decir, que acompañan de forma inseparable al producto audiovisual o son opcionales y el espectador puede elegir reproducirlos o no.

La siguiente categoría se centra en los métodos para proyectar los subtítulos. Desde la aparición de la subtitulación hasta hoy, los medios utilizados para incorporar el texto a la imagen han sido diversos, como el subtitulado mecánico, con láser o el electrónico. Por último, el formato del archivo audiovisual varía dependiendo del medio de distribución, que puede ser cine, televisión, DVD o internet (Díaz Cintas y Remael, 2007: 24).

Pese a las dificultades que supone esta modalidad, la subtitulación no deja de ser la modalidad de la traducción audiovisual más económica y más rápida de realizar, en comparación con otras modalidades como el doblaje; además de ser accesible para las personas con diversidad funcional auditiva.

\subsection{Los realia: contextualización y definición}

Es sabido que la traducción no solo consiste en trasladar el mensaje de una lengua origen a una lengua meta, sino que la traducción traslada también la cultura de la lengua origen (LO) a la lengua meta (LM).

Samovar y Porter (1997: 12-13) definen cultura como "el conjunto de conocimientos, experiencias, creencias, valores, significados, jerarquías, religión, nociones de tiempo, relaciones espaciales, conceptos del universo y objetos materiales y posesiones adquiridos por un grupo de personas a lo largo de generaciones a través del esfuerzo individual y grupal".

El referente cultural, como su nombre indica, hace referencia a una cultura, es un elemento portador de nociones culturales, por lo que cuando un traductor se enfrenta a la traducción de un referente cultural, se enfrenta a toda una cultura detrás que ha de conocer. Gracias a la traducción, hoy los puentes entre las diferentes culturas se hacen visibles. "La persona responsable del encargo realiza una doble operación: compara culturas y compara lenguas" (Igareda, 2011: 27). Por eso, hablar del referente cultural en cualquier proyecto sobre traducción es primordial, y más aún si cabe en este proyecto que está centrado, en parte, en el análisis de los referentes culturales en un caso de subtitulación del árabe al español, cuyas culturas están actualmente muy alejadas.

Las definiciones que ofrecen los especialistas y expertos en este ámbito son muchas, pero todas coinciden en la carga cultural que suponen dichos referentes. La falta de consenso reside en la denominación de este elemento: referente cultural, culturema, realia, elemento cultural, marca cultural o simplemente referente.

Santamaría (2001: 237) define los referentes culturales como "los objetos y eventos creados dentro de una cultura determinada con un capital cultural distintivo, intrínseco en el conjunto de la sociedad, capaz de modificar el valor expresivo que se otorga a los individuos que están relacionados al mismo". Mientras que Molina (2006: 79) formula una definición del referente cultural, teniendo en cuenta la traducción como "el elemento verbal o paraverbal que posee una carga cultural específica en una cultura y 
que al entrar en contacto con otra cultura a través de la traducción puede provocar un problema de índole cultural entre los textos origen y meta".

En este trabajo, se ha optado por la denominación realia, frente a las otras acepciones defendidas por otros autores. Vlakhov y Florin (1970: 432-456) introducen el término realia en traductología en 1970, y lo definen como el elemento textual que muestra un color social e histórico. Bödeker y Frese (1987:138), por su parte, amplían esta definición afirmando que se refiere a las realidades físicas e ideológicas propias de una cultura concreta.

\subsection{Clasificación de los realia}

En cuanto a la clasificación del referente cultural, cabe destacar que es una labor, aunque complicada, necesaria para facilitar la tarea de un traductor, debido a la profundidad y extensión de una cultura.

La clasificación más completa que abarca todos los posibles campos es la que propone Igareda (2011: 19-21), como herramienta metodológica aplicable a los diferentes géneros literarios y que pueda abarcar las numerosas manifestaciones culturales: 1. Ecología. 2. Historia. 3. Estructura social. 4. Instituciones culturales. 5. Universo social. 6. Cultura material. 7. Aspectos lingüísticos, culturales y humor.

Estas categorías contienen a su vez subcategorías, de las cuales veremos algunas en la parte práctica de este trabajo. Para la elaboración de esta clasificación, Igareda (2011) se ha basado en múltiples autores, apoyándose en diversos trabajos procedentes de diferentes disciplinas como los de Nida (1975), Poyatos (1976, 1983), Moreno (2003), Schwarz (2003), Villacampa (2004), entre otros. Cada uno de los estudios realizados sobre la clasificación del referente cultural se llevó a cabo partiendo de los estudios anteriores, añadiendo y ampliando las categorías de los referentes culturales. Por lo tanto, esta clasificación no es definitiva, porque la cultura no es estática y evoluciona.

Además, puede darse que un referente cultural con varias connotaciones se incluya en más de una categoría. Por ejemplo, "vuecencia" podría clasificarse como tratamiento entre personas dentro de la categoría: 5 . Universo social > 5.1. Condiciones sociales y hábitos sociales. Igualmente, podría clasificar también como "arcaísmo" dentro de la categoría: 7. Aspectos lingüísticos, culturales y humor > 7.3. Elementos culturales muy concretos.

\subsubsection{Técnicas y estrategias de traducción}

La traducción de los realia es uno de los principales retos a los que se enfrenta un traductor, por lo que, para superarlo, además de poseer un amplio conocimiento cultural en sus lenguas de trabajo, ha de ser capaz de conseguir la mejor traducción haciendo uso de la técnica o estrategia más adecuada. Los términos técnicas y estrategias se suelen emplear indistintamente en el ámbito de la traducción, sin embargo, son dos conceptos diferentes. Hurtado (2001: 256), define la técnica de traducción como "un procedimiento verbal concreto que es visible en el resultado de la traducción".

Una técnica es "un procedimiento traductológico que considera una traducción como un producto, y que se plantea en la primera fase del proceso de traducción e implica una toma de decisiones que afectan a todo el proceso traductológico". Mientras que una estrategia de traducción es "un procedimiento traductológico que considera la 
traducción como proceso, y que se aplica durante la fase de reexpresión para la resolución de problemas traductológicos concretos" (Sevilla y Sevilla, 2005).

Molina y Hurtado (2001: 498-512) crearon una tabla de dieciocho técnicas de traducción con sus respectivas explicaciones y ejemplos en su libro Translaion Technics Revised, a partir de un gran trabajo de recolección y de investigación en los estudios sobre la traducción. Todas estas técnicas son aplicables a cualquier género literario, pero algunas de las técnicas que aparecen en esta tabla son exclusivas de la traducción audiovisual. Como se puede ver en la tabla, la "variación" es una técnica que supone cambios dialectales, de tono o estilo; esta técnica es exclusiva para el doblaje. Por su parte, la "sustitución" es una técnica que puede utilizarse solamente en el doblaje o en la subtitulación, ya que consiste en la interpretación de gestos o entonaciones. Además, la "creación discursiva" es una técnica que se ve en la traducción de las películas, cuando el traductor tiene más libertad, y los títulos de las películas pueden crearse en vez de traducirse. A modo ilustrativo, recogemos las 18 técnicas propuestas por estas autoras: adaptación, ampliación lingüística, amplificación, calco, compensación, compresión lingüística, creación discursiva, descripción, elisión, equivalente acuñado, generalización, modulación, particularización, préstamo, sustitución, traducción literal, transposición, variación.

El objetivo de este proyecto no es crear una lista exhaustiva con todas las técnicas de traducción, sino analizar los realia extraídos del vídeo, clasificándolos y aplicando estas técnicas de traducción para su reexpresión en la lengua meta. Para ello, se ha recurrido a algunas de las técnicas proporcionadas por Molina y Hurtado (2001).

\section{Análisis y discusión de los resultados}

\subsection{Traducción íntegra del corpus de estudio}

Como ya se ha explicado en el apartado anterior, el corpus de estudio del presente trabajo es un archivo audiovisual, por lo que fue necesaria su transcripción (vid. anexo 1) a fin de una mayor comodidad para el lector interesado en su cotejo con la traducción íntegra que abordamos a continuación. $Y$ de ahí, poder extraer los referentes culturales que serán objeto de estudio y de análisis en los posteriores apartados.

Islam y Ciencia: Un enfoque educativo.

El proyecto Islam y Ciencia presenta: ¿Es cierta la inimitabilidad científica en el Corán?

El Dr. Nidhal Guessoum es profesor de Astrofísica en la American University of Sharjah (EAU). Ha publicado numerosos trabajos de investigación en el campo de los rayos gamma cósmicos y ha participado en muchas conferencias internacionales sobre ciencia. Además, ha presentado importantes contribuciones que giran en torno a la difusión y consolidación de la ciencia en la cultura arabo-islámica y la armonización entre la ciencia moderna, la religión y la filosofía. Ha publicado varios libros en árabe, inglés y francés, como: La historia del universo, junto con el profesor doctor Yamal Mimouni, y La armonización entre el islam y la ciencia moderna.

En las últimas décadas, se ha propagado la idea de la inimitabilidad científica en el Corán, después ha evolucionado también hacia la visión de la inimitabilidad científica en la Sunna del Profeta, e incluso se ha convertido en un gran fenómeno mundial, con importante proyección a través de conferencias, la televisión, los libros, la radio, la prensa, revistas, etc. 
También se enseña en las universidades y escuelas, y se incluye en planes de estudio, hasta el punto de que la gente empezó a considerarlo como algo sustancial en el islam, y que cualquier pregunta al respecto, o cualquier explicación o crítica, es considerada un insulto hacia la religión. Dios no lo quiera.

Por ello, queremos saber si realmente tiene fundamentos que la hacen tan esencial y que sea tan aceptada por la gente, o si realmente se ha difundido y se ha convertido en una moda ideológica y cultural. Pero, si la analizamos con más detalle, encontraremos que no se plantea con consistencia.

Hay muchos ejemplos fascinantes, como, por ejemplo, que existe la capacidad de calcular con exactitud la velocidad de la luz a partir de una única aleya, como en la siguiente: "Un día junto a tu Señor vale por mil años de los vuestros". Es decir, a partir de estas aleyas se calcula la velocidad de la luz y, con otras aleyas, se deduce la existencia de agujeros negros, de púlsares, del código genético, de la unificación de fuerzas físicas en el Corán, y otros ejemplos sorprendentes y deslumbrantes de los que no se conocen detalles y no se pueden demostrar. Tal vez se han tomado de forma superficial y sin ninguna consideración.

Se dice que Maurice Bucaille, el famoso médico, pensador y escritor francés, fue quien puso en marcha esta teoría. En 1976, publicó un libro en el que analizaba la Biblia, la Torá y el Corán desde un punto de vista científico, examinando cada versículo y observando si había contradicciones o errores científicos en alguno de estos libros. Al final, concluyó que tanto la Torá como la Biblia contienen muchos errores científicos, pero que el Corán no contiene ninguno, e incluso lo considera idéntico y consistente con todos los datos y descubrimientos científicos que conocemos hoy en día.

Pero hay una gran diferencia entre decir que el Corán no contiene errores científicos y que sus aleyas son idénticas y coherentes con lo que conocemos de la ciencia actual o aceptar una interpretación en consonancia con ello, y decir que hay información científica y precisa que ya apareció en el Corán hace más de 14 siglos y que la ciencia ha descubierto recientemente en el siglo XX.

La hipótesis de la inimitabilidad científica dice que hay una aleya en el Corán con información científica precisa y específica que desconocíamos durante la época del Profeta, que la paz y las bendiciones de Alá sean con él, y que la ciencia ha descubierto en el siglo XX. Esto se considera una inimitabilidad en el sentido de que está claro que estas aleyas son obra del Creador, quien inspiró esta información científica.

Sin embargo, cuando observamos realmente todos estos ejemplos que he mencionado desde una perspectiva crítica, ya sea el caso de la velocidad de la luz en el Corán, el del cálculo de la edad de la Tierra, es decir, 4,56 mil millones de años, o la edad del universo conocido hasta hoy, entre 13,8 y 13,9 mil millones de años y otros ejemplos mencionados, como los agujeros negros, el púlsar, etc., vemos que ninguno de estos ejemplos cumple la condición antes referida. Es decir, que esta información es precisa en el Corán y que precede a lo que ahora sí se conoce. Por ejemplo, cuando observamos la velocidad de la luz, esto ya lo he analizado, y no hay tiempo para mencionar todos los errores que aparecieron en ese análisis, que llevaron al autor de esa hipótesis, el fallecido Dr. Mansur Hasab Annabi, a afirmar que era un análisis científico y matemático erróneo y que no permite alcanzar la velocidad de la luz como lo han hecho.

También está la cuestión de los agujeros negros en la aleya: “¡Pues no! ¡Juro por los planetas, que pasan y desaparecen!" —una aleya que se ha interpretado como esos 
planetas que se mueven en el cielo, y que aparecen y desaparecen- ¿Cómo podemos decir que esta aleya explica, de modo riguroso, que haya agujeros negros y que tenemos información en el Corán acerca de los agujeros negros con sus características físicas?

Los expertos en la inimitabilidad científica escriben páginas y páginas a partir de esta aleya. Otro ejemplo es esta aleya sobre la luna: "Hemos determinado para la Luna fases, hasta que se pone como la palma seca". Los especialistas de la inimitabilidad científica dicen que esta aleya demuestra que la Luna gira alrededor de la Tierra y toma formas diferentes en cada fase, un proceso que se repite cada mes.

Sobre si esta información no se sabía antiguamente, decimos al respecto, primero, que la rotación de la Luna alrededor de la Tierra es conocida desde la eternidad. Desde el periodo neobabilónico hasta hoy, no se conoce a ningún astrónomo que dijera que la luna girara alrededor de la Tierra, y no había pruebas tajantes sobre eso.

Segundo, que Venus, por ejemplo, sabemos que también tiene fases como la luna y que se pone como la palma seca, al menos en el telescopio, y que no gira alrededor de la Tierra. El hecho de que tenga fases y se vuelva como la palma seca, no significa que un planeta o una luna o cualquier cuerpo celeste giren alrededor de la Tierra. Esto significa que los ejemplos que nos llegan y pretenden, de alguna manera, deslumbrar, no son tan rigurosos cuando los examinamos con precisión y de forma analítica como para que los musulmanes, científicos e intelectuales afirmen que hay una inimitabilidad científica en el Corán.

Y para finalizar, esta hipótesis de la inimitabilidad científica no puede considerarse como algo obvio e irrefutable en el islam, ya que muchos de los científicos más importantes de la civilización islámica antigua y moderna, como Sheikh Mohammad Abdu, que descanse en paz, Sheikh Rashid Radha, Sheikh Mahmoud Shaltot, que era el jeque de Al-Azhar, e incluso en Arabia Saudí, el científico saudí Sheikh Saud Arifi —quien publicó, en 2007, una investigación muy precisa y rigurosa respondiendo a dicha teoría - y otros escritores, incluyéndome a mí, criticamos todo esto. Sin embargo, existe aún la posibilidad de emplear la ciencia para interpretar el Corán, puesto que hay una diferencia entre la inimitabilidad científica y la interpretación científica del Corán.

Cuando vemos muchas aleyas coránicas que hablan sobre los cielos, las estrellas, los mares o los ríos, es útil y bueno emplear nuestro conocimiento científico para comprender lo que Alá quiere decir cuando habla, por ejemplo, de los mares o de cualquiera de esos fenómenos en los océanos, cielos, montañas, etc. Si utilizamos la ciencia para entender mejor el Corán, que es lo que se llama interpretación científica, pues no hay de qué preocuparse. Sino, al contrario, debemos leer el Corán con conocimiento y mayor conciencia, no basándonos en lo que decían los sabios antiguamente, especialmente si nuestros conceptos científicos han evolucionado, como mencioné hace un rato respecto a las fases o las formas tanto de la Luna como de Venus.

La explicación basada en una ciencia precisa y sólida la aceptamos sin discutirla, pero esto no significa ni supone que El Corán contenga información científica que precediese a los descubrimientos científicos hace ya muchos siglos. Este no es el objetivo del Corán, porque el Libro Sagrado es una guía espiritual y social para el ser humano y nunca tuvo la intención de transmitir a la gente información científica moderna. Muchas gracias. 


\subsection{Análisis y clasificación de los realia extraídos del corpus de estudio}

En este apartado, analizaremos los realia, siete en total, definiéndolos y encuadrándolas en sus correspondientes categorías. Se trata de una clasificación basada en la tabla propuesta por Igareda (2001: 19-21).

\begin{tabular}{|c|c|c|}
\hline Realia & Definición & Clasificación \\
\hline القرآن الكريم & $\begin{array}{l}\text { El Corán es el libro } \\
\text { sagrado de los } \\
\text { musulmanes, } \\
\text { directamente revelado al } \\
\text { Profeta por Dios, y } \\
\text { trascrito después de su } \\
\text { muerte (Abdelaziz, } \\
\text { 2004). }\end{array}$ & $\begin{array}{l}\text { 3. Estructura Social - } 3.7 \text { Religiones } \\
\text { "oficiales" o preponderantes } \rightarrow \text { Libro } \\
\text { Sagrado de la religión islámica }\end{array}$ \\
\hline السنة النبوية الثريفة & $\begin{array}{l}\text { La Sunna comprende las } \\
\text { palabras, actos, } \\
\text { aprobaciones, atributos y } \\
\text { la ((su)) vida (sirah) }((,)) \\
\text { del Profeta Mahoma, ya } \\
\text { sea antes de su Profecía } \\
\text { o después (Abu Mu'adh, } \\
\text { 2010: } 4) .\end{array}$ & $\begin{array}{c}\text { 4. Instituciones Culturales }-4.3 \\
\text { Cultura religiosa } \rightarrow \text { Tradición del } \\
\text { Profeta Mahoma } \\
\text { 3. Estructura Social }-3.7 \text {. Religiones } \\
\text { "oficiales" o preponderantes } \rightarrow \text { Islam } \\
\text { 3.6 Figuras respetadas } \rightarrow \text { El Profeta } \\
\text { Mahoma }\end{array}$ \\
\hline لا قدر الله & $\begin{array}{l}\text { Expresión religiosa de } \\
\text { los musulmanes que } \\
\text { puede tener como } \\
\text { equivalente en español: } \\
\text { "Que Dios/Alá no lo } \\
\text { quiera/permita" }\end{array}$ & $\begin{array}{c}\text { 4. Instituciones Culturales }-4.3 \\
\text { Cultura religiosa y creencias } \rightarrow \\
\text { Expresión religiosa }\end{array}$ \\
\hline 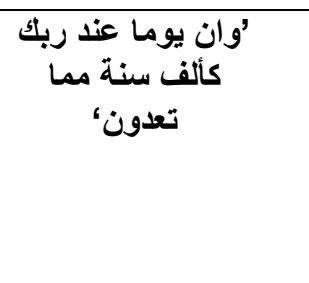 & $\begin{array}{l}\text { Versículo del Corán, } \\
\text { Sura Al-Haj: } 47 .\end{array}$ & $\begin{array}{l}\text { 4. Instituciones Culturales }-4.3 \\
\text { Cultura religiosa y creencias } \rightarrow \\
\text { Oraciones } \\
\text { 3. Estructura Social - } 3.7 \text { Religiones } \\
\text { "oficiales" o preponderantes } \rightarrow \text { Islam }\end{array}$ \\
\hline النبي صلى الله عليه & $\begin{array}{l}\text { Mahoma fue el último } \\
\text { profeta y el más } \\
\text { importante en la religión } \\
\text { musulmana. }\end{array}$ & $\begin{array}{c}\text { 3. Estructura Social- } \\
\text { 3.6 Figuras respetadas } \rightarrow \text { EI Profeta } \\
\text { Mahoma } \\
\text { 3.7 Religiones "oficiales" o } \\
\text { preponderantes } \rightarrow \text { Islam }\end{array}$ \\
\hline لا تقوم بهذه الصلابة & $\begin{array}{c}\text { Construcción } \\
\text { fraseológica propia de la } \\
\text { lengua árabe. Al no } \\
\text { existir el verbo "ser" } \\
\text { como tal en árabe, se } \\
\text { recurre a otros verbos }\end{array}$ & $\begin{array}{c}\text { 7. Aspectos lingüísticos, culturales y } \\
\text { humor - 7.1 Verbos determinados } \rightarrow \\
\text { Sintagma verbal }\end{array}$ \\
\hline
\end{tabular}




\begin{tabular}{|c|c|c|}
\hline & $\begin{array}{c}\text { que puedan realizar la } \\
\text { función del verbo "ser". }\end{array}$ & \\
\hline آية قرآنية & $\begin{array}{c}\text { Aleya es una palabra de } \\
\text { origen árabe que hace } \\
\text { referencia a cada uno de } \\
\text { los versículos del Corán, } \\
\text { es decir, cada una de las } \\
\text { breves divisiones de los } \\
\text { capítulos (suras) del } \\
\text { Libro Sagrado de los } \\
\text { musulmanes. }\end{array}$ & $\begin{array}{c}\text { 4. Instituciones Culturales - 4.3 } \\
\text { Cultura religiosa y creencias } \rightarrow \\
\text { Oraciones }\end{array}$ \\
& $\begin{array}{c}\text { 3. Estructura Social - 3.7 Religiones } \\
\text { "oficiales" o preponderantes } \rightarrow \text { Islam }\end{array}$ \\
\hline
\end{tabular}

Tras esta exposición, podemos decir que la Estructura Social (3) y las Religiones "oficiales" o preponderantes (3.7), junto con las Instituciones Culturales (4) y la Cultura religiosa y creencias (4.3) son las categorizaciones temáticas que más se dan en esta clasificación. Por ello, se observa que el ámbito predominante en el corpus objeto de estudio es el ámbito religioso, precisamente de la religión islámica, y la mayoría de los realia extraídos hacen referencia a cuestiones religiosas. Por lo tanto, es necesario mantener dichas connotaciones religiosas en el TM y recurrir a las estrategias y técnicas de traducción adecuadas para lograrlo.

\subsection{Análisis de las técnicas de traducción empleadas en la traducción de los realia}

\begin{tabular}{|l|l|l|c|}
\hline 1 & El Corán & Préstamo \\
& & & Elisión \\
\hline
\end{tabular}

En esta primera tabla, se ha traducido este sintagma por "el Corán", un préstamo del árabe en la lengua española, naturalizado, ya que se trata de una transliteración del árabe adaptada a las normas lingüísticas de la lengua meta. Además, en esta traducción se ha omitido el adjetivo que sería "Sagrado", porque es una connotación innecesaria para el público hispanohablante dado que el término Corán ya incluye esta connotación de "libro sagrado".

\begin{tabular}{|c|c|c|c|}
\hline 2 & $\begin{array}{c}\text { La Sunna del } \\
\text { Profeta }\end{array}$ & Traducción literal \\
& & & Elisión \\
& & & Préstamo \\
& & & Equivalente acuñado \\
\hline
\end{tabular}

En esta segunda, se observa que el sintagma se ha traducido "palabra por palabra", es decir, de forma literal, aunque omitiendo el adjetivo "Honorable" que le da una connotación religiosa. Se trata del equivalente acuñado en español de esta expresión, que a su vez es un préstamo naturalizado del árabe. En este caso, estamos ante una transliteración de la palabra "Sunna" adaptada a las normas lingüísticas de la lengua meta. 


\begin{tabular}{|c|c|c|c|}
\hline 3 & Dios no lo quiera & Equivalente acuñado \\
& & & لا قدر الله \\
& & & Generalización \\
\hline
\end{tabular}

La traducción de esta expresión consistió en la búsqueda de una expresión reconocida por el uso lingüístico en la lengua meta. Además, se ha optado por emplear para la traducción del término "Alá" un término general y neutro "Dios", que se utiliza para todas las religiones y no conlleva ninguna connotación o matiz diferenciador.

\begin{tabular}{|c|c|c|c|}
\hline 4 & 'وان يوما عند ربك كألف تعدون، & $\begin{array}{c}\text { "Un día junto a tu Señor } \\
\text { vale por mil años de los } \\
\text { vuestros". }\end{array}$ & Modulación \\
\hline
\end{tabular}

Aquí se trata de una reformulación léxica de la frase original, trasladando el sentido de la manera más comprensible en el texto meta.

\begin{tabular}{|l||l|c|c|}
\hline $\mathbf{5}$ & النبي صلى الله عليه وسلم & $\begin{array}{c}\text { El Profeta, que la paz y } \\
\text { las bendiciones de Alá } \\
\text { sean con él }\end{array}$ & Traducción literal \\
& & Transposición \\
\hline
\end{tabular}

En este ejemplo, se ha traducido esta frase literalmente, aunque dentro de esta traducción literal, se ha producido un cambio en la estructura de la frase original, de forma que los verbos en la frase de LO pasaron a ser sustantivos en la LM, es decir, se ha cambiado la categoría gramatical de estos. Además, el término "Alá" supone un préstamo, ya que es una transliteración naturalizada del árabe y adaptada a las normas lingüísticas del español.

\begin{tabular}{|l|l|l|l|}
\hline 6 & No es tan consistente & Modulación \\
\hline
\end{tabular}

La traducción de esta frase consistió en una reformulación léxica desde un enfoque distinto, transmitiendo así el sentido correcto, de manera que la frase sea natural en la LM.

\begin{tabular}{|c|c|c|c|}
\hline 7 & آية قرآنية & Aleya & Equivalente acuñado \\
& & & Elisión \\
\hline
\end{tabular}

Se ha optado por traducir este sintagma por su equivalente acuñado en la lengua española "aleya", para mantener su raíz árabe, pudiendo traducirlo como "verso coránico", que sería una traducción literal, o "versículo". Al optar por la traducción "aleya", se ha omitido el adjetivo "coránico" porque el término acuñado ya incluye esa connotación. 
Como podemos ver, en la traducción de los referentes culturales se puede dar más de una técnica al mismo tiempo. A veces, los traductores traducen recurriendo a varias técnicas sin darse cuenta, y la decisión de traducir un término de una o de otra forma queda a juicio del traductor, siempre y cuando sea capaz de justificar su traducción.

\subsection{Resultados}

\begin{tabular}{|c|c|}
\hline Técnica de traducción & $\mathrm{N}^{\circ}$ de veces que se emplea \\
\hline Adaptación & - \\
\hline Ampliación lingüística & - \\
\hline Amplificación & - \\
\hline Calco & - \\
\hline Compensación & - \\
\hline Compresión lingüística & - \\
\hline Creación discursiva & - \\
\hline Descripción & - \\
\hline Elisión & 3 \\
\hline Equivalente acuñado & 3 \\
\hline Generalización & 1 \\
\hline Modulación & 2 \\
\hline Particularización & - \\
\hline Préstamo & 3 \\
\hline Sustitución & - \\
\hline Traducción literal & 2 \\
\hline Transposición & 1 \\
\hline Variación & - \\
\hline
\end{tabular}

Basándonos en estas cifras, podemos concluir que las técnicas que más se han utilizado en la traducción de los realia son el equivalente acuñado, la elisión y el préstamo. La predominancia del préstamo, así como del equivalente acuñado, hace ver nuestra fidelidad al TO y la intención de reflejar en el TM matices religiosos e idiomáticos. Sin embargo, la elisión parece algo contraria a dicha fidelidad, pues una de las particularidades del árabe es la extensión en adjetivos, y sobre todo en el ámbito religioso. Dicha extensión resulta redundante e innecesaria en español, por lo que, para respetar la naturalidad y fluidez de la redacción en el TM, fue necesario 
omitir algunos adjetivos. La fidelidad al TO se aprecia, además, en la aplicación de la técnica de traducción literal, aunque con las reformulaciones léxicas y estructurales necesarias.

La modulación y transposición se deben, en este caso, a las diferencias sintácticas del árabe con respecto al español, y por ello, en las traducciones de textos árabes al español se requiere el uso de estas dos técnicas que suponen reformulaciones fraseológicas en el TM.

\section{Discusión. Reflexiones sobre el proceso de subtitulado}

Después de analizar las técnicas y estrategias aplicadas en la traducción de los realia y ofrecer resultados cuantitativos de estas, y teniendo en cuenta que el objetivo de nuestra anterior traducción es su reflejo en subtítulos, consideramos necesario describir el proceso de subtitulado que se ha seguido en la subtitulación del corpus objeto de estudio.

Traducir implica el buen conocimiento tanto de la lengua de origen como de la lengua meta para lograr realizar una traducción de calidad, siendo fundamental, de la misma manera, la riqueza de léxico y una amplia cultura general de los países de ambas lenguas. Cualquier buen traductor que posea dichas competencias puede traducir cualquier género textual y de la temática que sea, haciendo, por supuesto, un bueno uso de la documentación. Esta labor de documentación antes, durante y después de una traducción es esencial e imprescindible para el resultado final del producto, puesto que una mala o nula documentación puede llevar a cometer importantes errores, que van de la imprecisión terminológica a la ausencia parcial o total de sentido; y esto es perfectamente aplicable a la subtitulación.

La subtitulación interlingüística, como ya se explicó al principio de este trabajo, es una modalidad de la traducción audiovisual que implica una traducción escrita del texto oral. Esta actividad es llevada a cabo por un traductor cualificado capaz de trasladar el mensaje claro y exacto de una lengua origen a una lengua meta. En cuanto a la subtitulación intralingüística, cuyo cometido corresponde a la reformulación del texto oral en el mismo idioma, es una tarea que se puede llevar a cabo por un lingüista o especialista en la temática del contenido del archivo audiovisual.

Sin embargo, la subtitulación intralingüística engloba también los subtítulos para dialectos de la misma lengua (Cintas y Remael, 2009: 13-24), y en este caso sí que se trata, en parte, de una traducción, ya que la persona que subtitula ha de ser competente tanto en la lengua como en sus variedades, como es el caso del árabe.

Un texto oral, al igual que un texto escrito, plantea dificultades a la hora de realizar el proceso de traducción, que, a veces, pueden ser las mismas como es el caso de la terminología. Pero, generalmente, un texto oral no posee la misma cohesión y coherencia que el texto escrito, porque este primero no deja de ser un discurso oral que da lugar a improvisaciones, autocorrecciones, reiteraciones, redundancias, desvíos del tema principal, etc. Ejemplos de esta índole, lo podemos ver en un pasaje de la transcripción del archivo audiovisual objeto de estudio del presente trabajo, donde el orador no emplea más de cinco verbos durante 40 segundos en un texto de 80 palabras, además se desvía continuamente del tema principal:

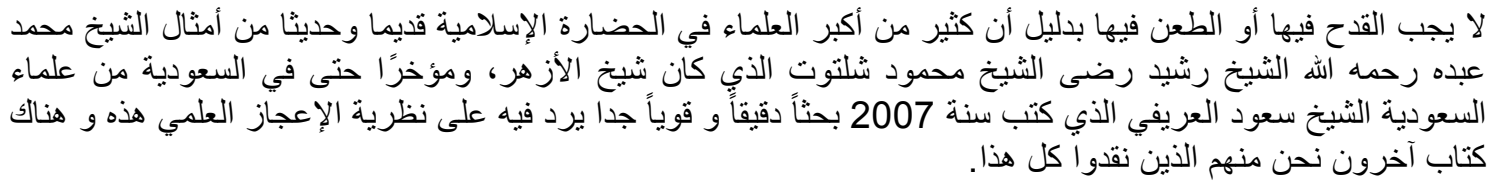


Además, en algunas obras audiovisuales, el traductor ha de enfrentarse a la dificultad de transmitir el mensaje de ciertas imágenes en los subtítulos para que se refleje el mismo sentido, como ocurre, por ejemplo, en el caso de películas de género cómico donde las bromas y gags no siempre forman parte del discurso oral; y no nos olvidemos de la dificultad que supone traducir un texto oral de un registro coloquial a una lengua meta muy alejada cultural y lingüísticamente de la lengua de origen.

Sin embargo, subtitular no es solo traducir, sino que es un conjunto de tareas que el traductor debe realizar para conseguir un producto final satisfactorio. Generalmente, para la subtitulación de un archivo audiovisual, puede que el traductor disponga de material escrito como puede ser una lista de diálogos o un guion. En nuestro caso, se ha llevado a cabo la transcripción del texto oral para su posterior traducción, y una vez analizado y traducido el contenido del mencionado archivo, se procedió a la introducción de los pasajes traducidos a modo de subtítulos en el archivo.

Cabe recordar que la introducción de subtítulos es la parte práctica de este proceso e implica el manejo de un programa informático determinado. Existen varios programas de subtitulado, algunos gratuitos y otros no, como Subtitle Workshop, Belle Nuit Subtitler, Annotation Edit, Jubler para MAC, etc. En el presente trabajo, se ha empleado el programa Subtitle Workshop versión $6.0 \mathrm{~b}$, ya que esta versión ofrece opciones avanzadas de regulación de tiempo y de caracteres. La elección de un programa $u$ otro depende del traductor y del resultado que quiera conseguir. En cualquier caso, el proceso de subtitulado, los retos, condiciones y limitaciones que este supone son iguales en todos los programas.

En la subtitulación, la traducción escrita del texto oral objeto de estudio ha sufrido cambios porque fue necesario resumir mucho por las limitaciones de espacio y de tiempo (14 caracteres por segundo). Según el tipo de texto, a veces solo se puede llegar a traducir el $70 \%$ del texto original, puesto que hay que prescindir de términos, resumir, abreviar, etc., debido a que los subtítulos no pueden durar más de 6 segundos, y a veces se dan varios mensajes a la vez (simultaneidad de mensajes). La duración de los subtítulos no es un dato seleccionado aleatoriamente, sino que está basado en que aquella persona que esté leyendo los subtítulos tenga el tiempo suficiente y necesario para hacerlo. Todas estas condiciones sitúan al traductor en la delicada labor de reformular y resumir los subtítulos lo máximo posible, conservando, en todo momento, el sentido del discurso.

Por último, mencionamos otro elemento de máxima relevancia en todo este proceso; nos referimos a la sincronización, que es la última tarea en la cadena de subtitulado antes de la revisión final. "El traductor de subtitulado ajusta 'de oído', adaptando la duración de su traducción a la permanencia de las imágenes/palabras correspondientes en pantalla" (Mayoral, 1997: 3). Es importante que la duración del subtítulo sea suficiente para su lectura, ya que el guion audiodescriptivo ha de aparecer dos o tres segundos antes de la imagen.

\section{Conclusiones}

El presente trabajo se centra, en primer lugar, en la subtitulación como modalidad de la traducción, y en segundo lugar, en la traducción de los referentes culturales. Tras una exhaustiva investigación sobre la subtitulación, podemos afirmar que es una de las modalidades de traducción más solicitadas en la actualidad, y que le supone a un traductor ampliar sus habilidades y competencias hacia el manejo de determinados programas informáticos y la solución de retos de subtitulación. 
La traducción de los referentes culturales o realia siempre supone un reto para el traductor, ya que cada lengua tiene sus propias particularidades, que afectan no solo a la traducción, sino también a la subtitulación, como es el caso del árabe. La lengua árabe posee una enorme carga cultural, sobretodo religiosa, por lo que es elevada la presencia de referentes culturales en los textos redactados en árabe, aunque el tema no sea precisamente religioso. En el caso del corpus objeto de estudio del presente trabajo, el tema es claramente religioso, de ahí que la mayoría de los referentes culturales extraídos se encuadran en categorías religiosas, como se ha podido observar tras su clasificación y categorización.

Tras la clasificación de los referentes culturales, con el objetivo de conocer a fondo cada realia y sus connotaciones para una traducción óptima, observamos que la mayoría de los realia se encuadran en más de una categoría. Por ello, concluimos que los referentes culturales pueden tener más de una connotación que se debe tener muy en cuenta a la hora de traducir. Así, para la traducción de los realia fue necesario reflejar, en el texto meta, dichas connotaciones religiosas, que aluden a la religión islámica, mediante el recurso a técnicas de traducción como el préstamo o la traducción literal.

Finalmente, cabe subrayar la complejidad de transmitir el mensaje mediante subtítulos debido a las restricciones de tiempo y espacio que supone esta modalidad de traducción. Por ello, el traductor de subtítulos ha de encontrar soluciones lingüísticas como puede ser la elisión o la modulación, con el fin de transmitir correctamente el mensaje dentro de los límites de espacio y tiempo contemplados en el uso y en la práctica de la subtitulación.

\section{Referencias}

\begin{tabular}{l} 
Abdelaziz, M. (30, mayo, 2018). Velos sobre las mujeres. \\
$\begin{array}{l}\text { [Archived } \\
\text { http://www.webcitation.org/70yguxC4l] }\end{array}$ \\
\hline
\end{tabular}

Abu Mu'adh, H.A.M. (30, mayo, 2018). La Sunnah auténtica es revelación de Al-lah y

está protegida 3. [Archived by WebCite $®$ at
http://www.webcitation.org/715WW2Oia]

Agost Canós, R. (1996). La traducció audiovisual: el doblatge. Tesis Doctoral, Universitat Jaume I.

Agost Canós, R. (1999). Traducción y doblaje: palabras, voces e imágenes. Barcelona: Ariel.

Bödeker, B. y Freese, K. (1987). Die Übersetzung vonRealienbezeichnungen bei

literarischen Texten: Eine Prototypologie. TextconText, 2(3), $137-165$.

Chaume Varela, F. (2004). Cine y traducción. Madrid: Cátedra.

Chaume Varela, F. (2001). La traducción en los medios audiovisuales. Castellón: Publicacions de la Universitat Jaume I.

Díaz Cintas, J. y Remael, A. (2007) Audiovisual translation: Subtitling. Manchester: St Jerome.
Hatim, B. y Mason, I. (1990/1995). Discourse and the Translator.Londres: Longman / (Teoria de la traducción. Una aproximación al discurso. Barcelona: Ariel.

Hewson, L. y Martin, J. (1991). Redefining Translation. The Variational Approach. Londres: Routledge.

House, J. (1997). Translation quality assessment: A model revisited. Tubinga: Gunter.

Hurtado Albir, A. (2001). Traducción y traductología. Madrid: Cátedra.

Igareda, P. (2011). Categorización temática del análisis cultural: una propuesta para la traducción. Íkala, revista de lenguaje y cultura, 16(27), 11-32.

Isa García, M. (20, marzo, 2018). Traducción del Corán al español. The Nobel Qur'an. [Archived by WebCite® at http://www.webcitation.org/70yiJ2cai].

Lafarga, F. (1999). La traducción en España (1750-1830): lengua, literatura, cultura. Lleida: Edicions de la Universitat de Lleida.

Martínez Molina, L. (2006). El otoño del pingüino: análisis descriptivo de la traducción de los culturemas. Castellón: Universitat Jaume $\mathrm{I}$.

Molina, L. y Hurtado Albir, A. (2002). Translation techniques revisited: A dynamic and functionalist approach. Méta, 47(4), 363-648. 
Reiss, K. y Vermeer, H. (1984/1996). Grundlegung einer allgemeinen Translationstheorie. Tubinga: Niemeyer / (Fundamentos para una teoría funcional de la traducción. Madrid: Ediciones Akal).

Samovar, L. y Porter, R. (1997). Intercultural Communication: a reader.Belmont: Wadsworth Publications.

Santamaría, L. (2001). Subtitulació i referents culturals. La traducció com a mitjà d'adquisició de representacions mentals. Tesis Doctoral, Universitat Autònoma de Barcelona.

Seleskovitch, D. y Lederer, M. (1984). Interpréter pour traduire. Paris : Didier Erudition.
Sevilla Muñoz, J. y Sevilla Muñoz, M. (11, mayo, 2018). Técnicas y estrategias de traducción. [Archived by WebCite $\AA$ at http://www.webcitation.org/7102KkDnZ]

Snell, M. H. (1988). Translation Studies: An Integrated Approach. Amsterdam: Jhon Benjamins.

Vinay, J.P. y Darbelnet, J. (1958). Stylistique comparée du français et de l'anglais. Méthode de traduction. Paris: Didier.

Vlakhov, S. y Sider, F. (1970): Neperevodimoe v perevode: realii, in Masterstvo perevoda. Moscú: Sovetskii pisatel. 


\section{Anexos}

\section{Transcripción de archivo audiovisual}

\section{(Archived by WebCite ${ }^{\circledR}$ at http://www.webcitation.org/715a09k30)}

Véase online: https://www.youtube.com/watch?v=7eOXL83re4w

مشروع الإسلام والعلم: نهج تعليمي و العلم يقدم: ما صحّة نظرية الإعجاز العلمي في القرآن الكريم؟

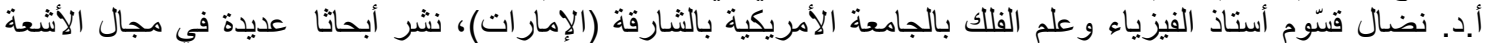

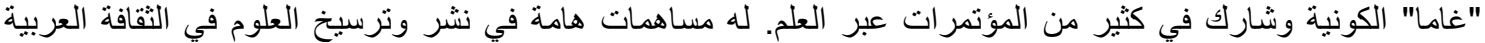

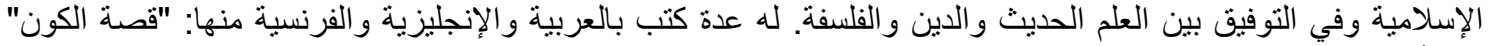

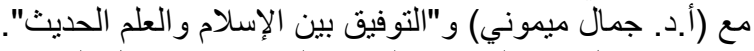
انتشرت خلان هذه السنوات الكثيرة التي مضت الإن خلال العقدين أو الثناثة الأخيرة فكرة الإعجاز العلمي في القرآن آن الكريم ثم

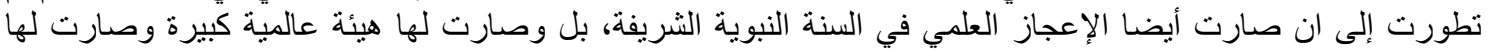

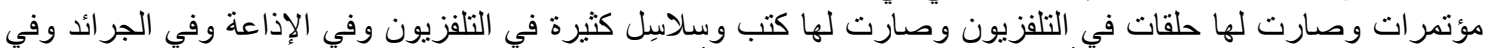

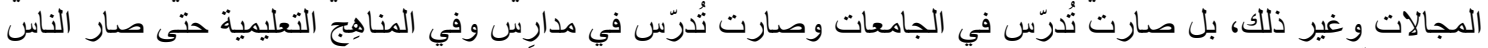

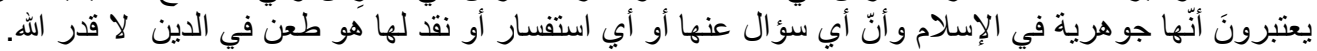

لذلك نريد أن نسأل هل حقيقة لها من الدعائم ما يجعلها جوهرية بهذا الشكل ويجعل لها هذا القبول بين الناس أم أن حقيقة انتشرت وصارت تشبه موضا فكرية ثقافية، ولكن إذا نظرنا إليها بنظرة متفحصة نجد نهد أنها لا تقوم بهذه الصلابة.

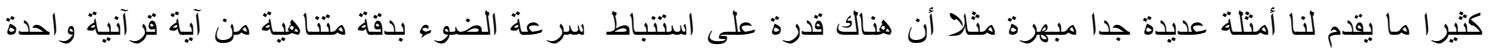

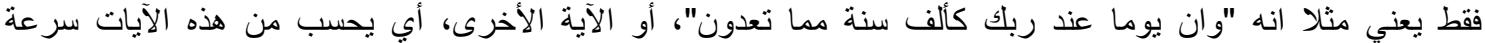

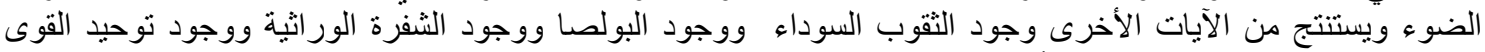

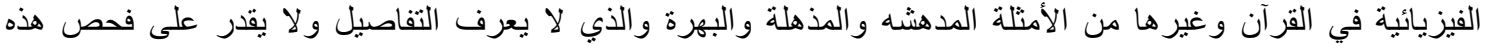

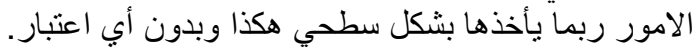

كثير ما يقال أن هذه النظرية أو هذه الفرضية هذا الطرح ظهر وانفجر مع موريس بوكايلي المفكر الطبيب الكاتب الفرنسي

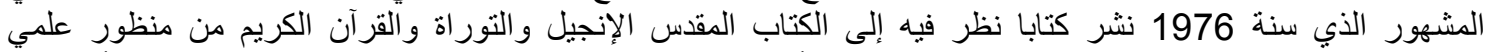

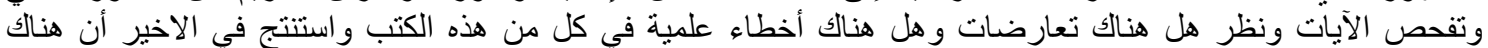

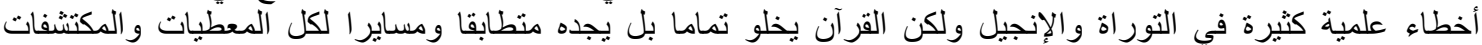

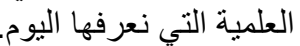

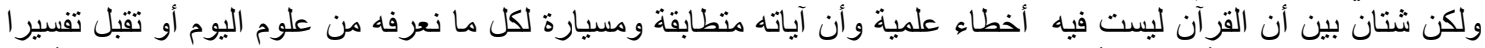

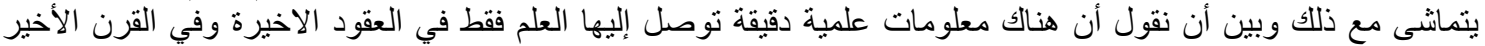

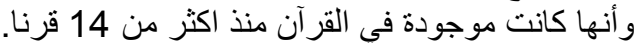

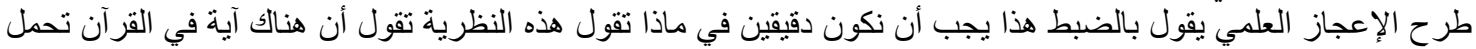

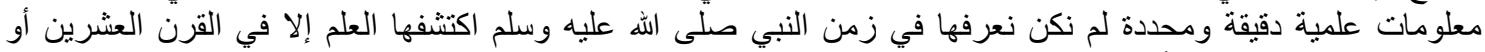

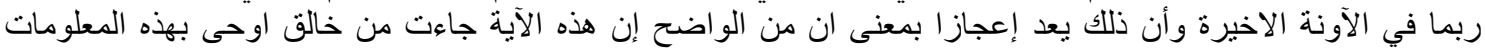

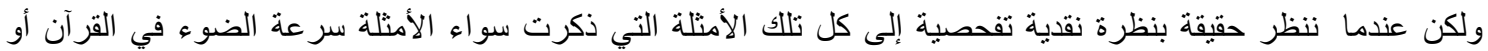

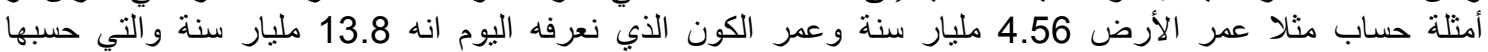

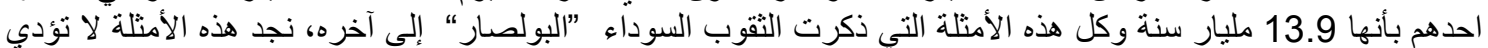

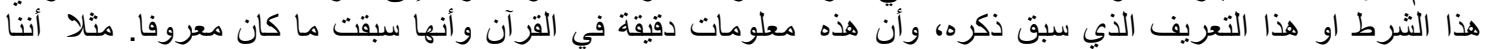

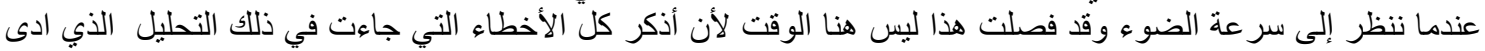

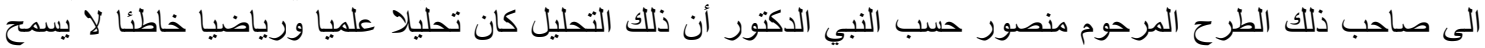

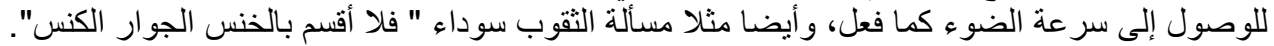

كيف يمكن أن نقول أن "فلا أقسم بالخنس الجوار الكنس" التي كانت دائما تفسر على أنها تلك الكواكب السيارة التي في

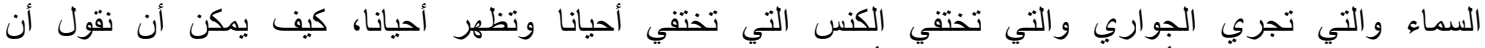
هذه توضح بشكل صنارم أن هنأك ثقوب سوداء و وأن عندنا معلومات في القرآن عن الثقوب السوداء بمو اصفاتها الفيزيائية . 
يعني أصحاب الإعجاز العلمي يكتبون لنا صفحات طويلة من خلال هذه الآية مثلا ثم أمثلة أخرى يعني مثلا نأتي إلى القمر

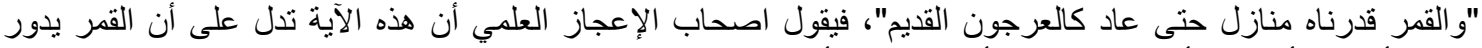

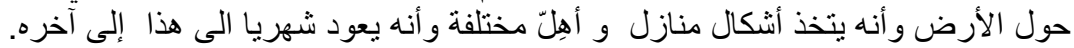

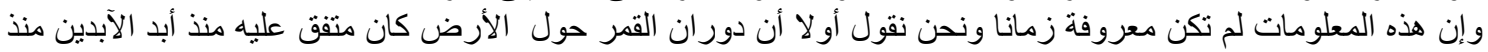

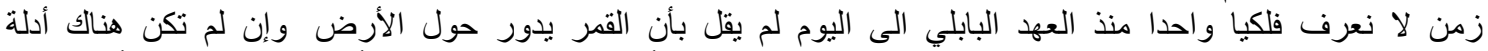

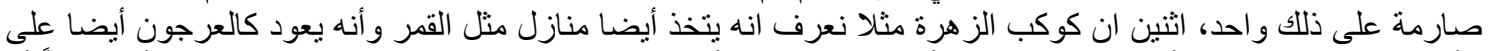

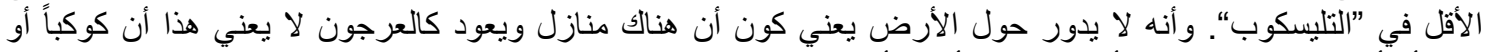

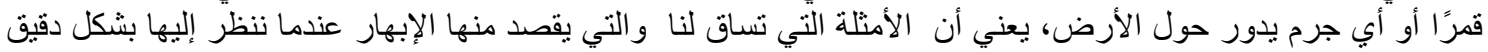

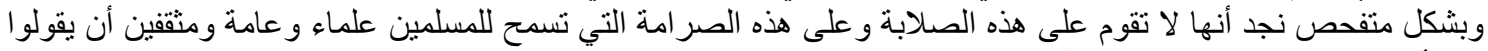

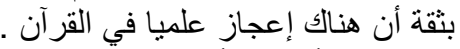

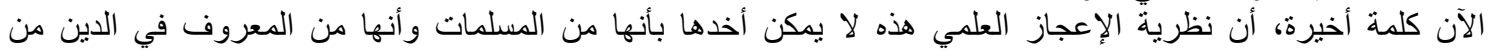

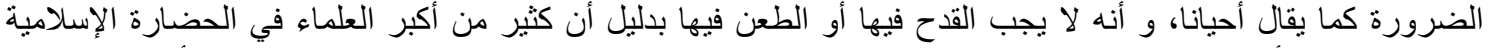

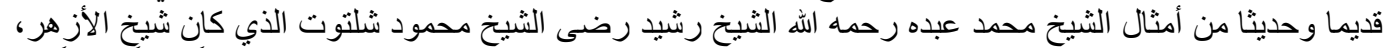

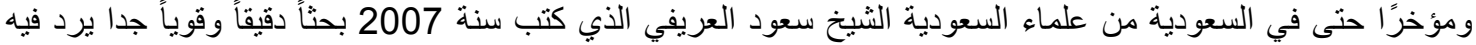

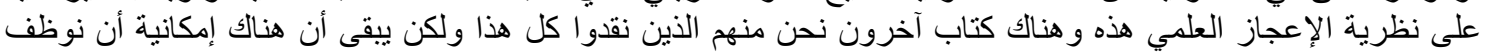

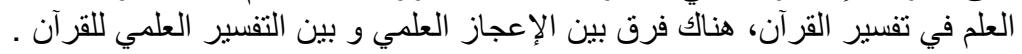

عندما ننظر إلى الكثير من الآيات القر آنية التي تتكلم عن السموات أو التي تتكلم عن النجوم أو عن البحار أو عن الأنهار إلخ إلخ

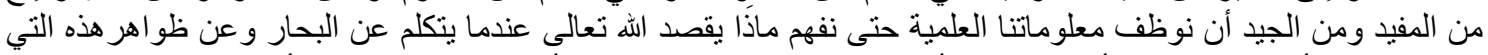

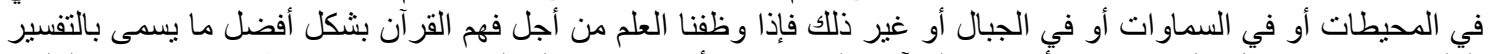

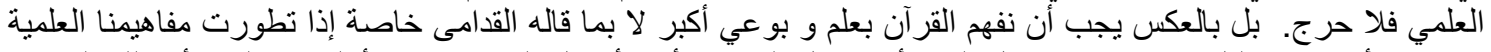

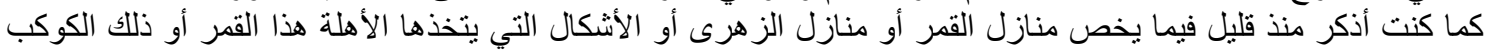

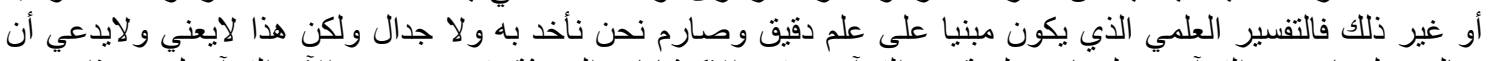

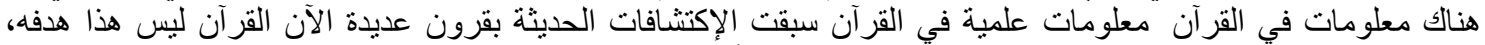

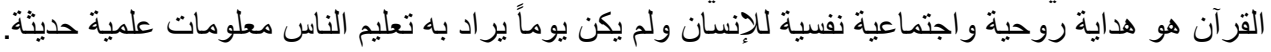

\section{Archivo audiovisual subtitulado}

Véase aquí:

(Archived by WebCite ${ }^{\circledR}$ at http://www.webcitation.org/715aZ0jdc)

https://www.youtube.com/watch?v=YhAcUEzLmso\&feature=youtu $\cdot$ be $^{2}$

\footnotetext{
${ }^{2}$ Seleccione la opción de "subtítulos".
} 